\title{
Serological diagnosis of Helicobacter pylori- evaluation of four tests in the presence or absence of non-steroidal anti-inflammatory drugs
}

\author{
A S Taha, J Reid, P Boothmann, C G Gemmell, F D Lee, R D Sturrock, R I Russell
}

\begin{abstract}
The host's humoral immune response to Helicobacter pylori has been used in the diagnosis of active infection with these organisms. Several commercial tests are available but there are few and unconfirmed reports of their efficacy. This study aimed to assess and compare the efficacy of the following $H$ pylori serological tests in patients treated or not treated with non-steroidal anti-inflammatory drugs (NSAID): Pyloriset Latex, Helico-G, Biolab Malakit, and Bio-Rad GAP Test IgG. Venous blood was tested at random in 124 patients, 64 of whom had received NSAID and 60 who had not. $H$ pylori IgG antibodies were detected by latex agglutination (Pyloriset), or by ELISA (the remaining tests). Endoscopic gastric antral biopsy specimens were also obtained for urease activity, culture, and histology. Detection of $\boldsymbol{H}$ pylori by at least two of these was considered as a true positive, and its absence in all biopsy specimens as a true negative. The sensitivity values in the presence (or absence) of NSAID were: Pyloriset Latex, 59 (60)\%; Helico-G, 79 (74)\%; Biolab Malakit, 85 (81)\%; and Bio-Rad GAP Test IgG, $100(95) \%$. The respective specificity values were: $50(71) \%, 47(59) \%, 50(65) \%$, and 30 (29)\%. The Bio-Rad GAP Test IgG has the highest sensitivity and the lowest specificity values regardless of NSAID intake. The sensitivity of the other tests, however, is less than that of the standard biopsy related tests and their specificity is even lower in chronic NSAID users.
\end{abstract}

(Gut 1993; 34: 461-465)

It is realised increasingly that the systemic immune reponse to Helicobacter pylori infection confers no protection against the organisms, and its presence is of diagnostic value only.' Several methods have been used to detect this response, including agglutination, complement fixation, and enzyme linked immunosorbent assay (ELISA). ${ }^{2-8}$ The low cost and convenience of these techniques encouraged some workers to recommend their use in the diagnosis and management of $H$ pylori associated ulcers, without the need for endoscopy. ${ }^{910}$ Because of their diagnostic and therapeutic importance, increasing numbers of commercial serological tests are being introduced. The validity of these tests, however, has been assessed by few and unconfirmed studies, in patients who were not taking NSAID, and direct comparison between them has been lacking. Recent evidence indicates that the prevalence of NSAID related ulcers is higher in those infected with $H$ pylori ${ }^{11-13}$ (which emphasises the need for accurate diagnosis of this infection in these patients) and that the specificity of some serological tests can be influenced by NSAID. ${ }^{14}$

This study aimed to evaluate the efficacy of four newly introduced commercial tests (Pyloriset Latex; Helico-G; Biolab Malakit; and Bio-Rad GAP Test IgG) in diagnosing $H$ pylori in patients with or without a history of chronic NSAID intake.

\section{Patients and methods}

Patients with adult rheumatoid arthritis (the NSAID group) were recruited from the rheumatology outpatient clinic provided they had taken their NSAID for at least 4 weeks. The rest of the patients were recruited from the gastroenterology outpatient clinic, where they had presented with transient or persistent abdominal complaints. They were excluded if they had been treated with steroids, cytotoxic drugs, antibiotics, anti-ulcer drugs, or if they had had gastroduodenal surgery.

Venous blood $(10 \mathrm{ml})$ was taken for serology tests and patients underwent endoscopy at random using 4-6 mg midazolam for sedation, after having given informed consent. A total of four gastric antral biopsy specimens were taken for histology (two specimens), culture (one specimen), and CLO test (one specimen). Ulcers were also biopsied to exclude malignancy.

$H$ pylori was identified by culture and histology as previously described. ${ }^{15}$ The classification of gastritis was according to the Whitehead system modified to include the newly described entities of lymphocytic and chemical gastritis. ${ }^{13-17}$.

The CLO test (Delta-West Ltd, Bentley, Western Australia) was carried out by placing the antral biopsy specimen into the gel pellet, and reviewing the slide for the positive red colour at 3 and 24 hours.

The Pyloriset Latex (Orion Diagnostica, Finland) and the Helico-G (Porton Cambridge, Maidenhead, UK) tests were carried out according to the manufacturers's instructions and as recently described. ${ }^{1+}$ The Pyloriset detects IgG antibodies by agglutination, using Latex particles coated with acid extracted antigen of $H$ pylori. The Helico-G test uses an ELISA to measure IgG antibodies directed against $H$ pylori cell membrane derived antigen.

An ELISA was also used to detect IgG antibodies against two more partially purified antigens: $H$ pylori urease antigen, by Biolab Malakit (Biolab, Limal, Belgium), and $H$ pylori outer membrane antigen, by Bio-Rad GAP test IgG, 
(Bio-Rad Chemical Division, Richmond, Ca, USA). Both tests were also carried out according to the manufacturers' instructions. With the Biolab Malakit test, the diluted samples and controls were incubated in microwells precoated with $H$ pylori antigens at $37^{\circ} \mathrm{C}$ for 45 minutes to form an $H$ pylori antigen-antibody complex. The unbound components were washed off. An antiIgG coupled peroxidase conjugate was then added and incubated. The unbound conjugate was washed off, a substrate was added and incubated, and the reaction was finally stopped with $\mathrm{NaOH}$. The absorbance was read at 405 $\mathrm{nm}$, with the intensity of the green colour being proportional to the amount of anti- $H$ pylori antibodies in the sample. A sample was considered positive for $H$ pylori of its optical density was higher than the limit of the normal value, specified by the manufacturer. In the Bio-Rad GAP test, $100 \mu \mathrm{l}$ of standards, controls, and diluted patient samples were pipetted into the relevant nicrowells, and incubated for 60 minutes at $25^{\circ} \mathrm{C}$. The contents were then discarded, the wells were washed with the wash buffer solution and blotted on a paper towel. Anti-IgG enzyme conjugate solution was added to the wells, incubated for 30 minutes, washed, and freshly prepared substrate was added before incubating the plate in the dark for $\mathbf{1 0}$ minutes. Stop solution was added after blue colour development, and the absorbance was read at $450 \mathrm{~nm}$. A standard curve was constructed, and a sample was considered positive for $H$ pylori if its antibody concentration was greater than 17 units.

A true positive was defined as a patient who had $H$ pylori identified by at least two of the biopsy related tests (histology, culture, and CLO tests), while a true negative was one who did not have $H$ pylori diagnosed by any of these tests. Patients were excluded when $H$ pylori was found by only one of the three biopsy related tests.

Sensitivity was defined as the frequency of a positive test in all subjects with $H$ pylori infection, and specificity was the frequency of a negative test in those without the infection.

TABLE I Patients' general characteristics

\begin{tabular}{lll}
\hline & \multicolumn{2}{l}{ Patient group } \\
\cline { 2 - 3 } & On NSAID & Not on NSAID \\
\hline No & 64 & 60 \\
Men & 18 & 19 \\
Women & 46 & 41 \\
Age (y) median & 55 & 50 \\
(interquartile range) & $(43-65)$ & $(38-65)$ \\
Smokers & 25 & 21 \\
Drinkers & 31 & 34 \\
Abdominal symptoms & 25 & 39 \\
\hline
\end{tabular}

TABLE II Patients positive for Helicobacter pylori classified according to their histological findings (NSAID present (NSAID absent)

\begin{tabular}{|c|c|c|c|c|c|c|}
\hline \multirow[b]{2}{*}{ Histology } & \multirow[b]{2}{*}{$\begin{array}{l}\text { Total no } \\
\text { patients }\end{array}$} & \multicolumn{5}{|c|}{ Patients positive for $\mathrm{H}$ pylori } \\
\hline & & $\begin{array}{l}\text { Standard } \\
\text { tests }\end{array}$ & $\begin{array}{l}\text { Pyloriset } \\
\text { Latex }\end{array}$ & ${ }_{G}^{\text {Helico- }}$ & $\begin{array}{l}\text { BioLab } \\
\text { Malakit }\end{array}$ & $\begin{array}{l}\text { Bio-Rad GAP } \\
\text { Test IgG }\end{array}$ \\
\hline $\begin{array}{l}\text { Normal histology } \\
\text { Chronic superficial gastritis } \\
\text { Chemical gastritis } \\
\text { Lymphocystic gastritis } \\
\text { Chronic atrophic gastritis }\end{array}$ & $\begin{array}{l}10(12) \\
41(40) \\
9(2) \\
4(3) \\
0(3)\end{array}$ & $\begin{array}{l}1(5) \\
30(34) \\
1(0) \\
4(3) \\
0(3)\end{array}$ & $\begin{array}{c}2(3) \\
24(27) \\
5(0) \\
3(3) \\
0(1)\end{array}$ & $\begin{array}{l}1(5) \\
34(31) \\
5(0) \\
2(3) \\
0(2)\end{array}$ & $\begin{array}{c}1(5) \\
36(32) \\
5(0) \\
3(3) \\
0(2)\end{array}$ & $\begin{array}{l}6(8) \\
39(38) \\
6(1) \\
4(3) \\
0(3)\end{array}$ \\
\hline
\end{tabular}

Statistical analyses were performed with $\chi^{2}$ and McNemar's tests, ${ }^{18}$ with correction for multiple comparisons where appropriate. All specimens carried code numbers and were assessed under randomised conditions. The study was approved by the local ethics committee.

\section{Results}

Four of the 128 patients studied were excluded because $H$ pylori was identified in histological specimens only and could not be confirmed by culture or CLO test. The remaining 124 patients entered the final analysis: 64 took NSAID and 60 did not.

The demographic details of the patients are shown in Table I. The groups were comparable for age, smoking, and drinking habits but those not treated with NSAID were more likely to have abdominal complaints. The median duration of NSAID intake was $2 \cdot 5$ years.

Table II shows the prevalence of $H$ pylori, as detected by the various tests, in patients with histological abnormalities. Chronic superficial gastritis was the commonest histological abnormality regardless of NSAID intake; similar numbers of patients with this abnormality, who were also postive for $H$ pylori, were identified by Helico-G and Biolab Malakit compared with the standard (or biopsy related) tests. However, Pyloriset Latex identified the lowest number and the Bio-Rad GAP test diagnosed the highest number of patients with both $H$ pylori and chronic superficial gastritis. Chemical gastritis was found more commonly in patients taking NSAID: $H$ pylori organisms were seen in only one of nine patients, using the standard tests, but there were six seropositive cases with this histological entity using Bio-Rad test, and five seropositive patients using the remaining three tests. In addition, a total of $19(29 \%)$ patients treated with NSAID were found to have peptic ulcers, compared with seven (11\%) patients who were not taking NSAID. Erosion were found only in patients taking NSAID.

The overall efficacy of the serological tests in diagnosing $H$ pylori infection is shown in Table III and Figures 1 and 2. The Helico-G and Biolab Malakit tests had a similar efficacy. The Bio-Rad GAP Test, however, had the highest number of true and false positives and, as a result, the highest sensitivity and the lowest specificity regardless of NSAID intake. The specificity of the Pyloriset Latex, Helico-G, and Biolab Malakit tests was lower in the NSAID users. Pyloriset Latex had the lowest sensitivity and highest specificity in patients not taking NSAID.

It is also worth noting that the prevalence of $H$ pylori in patients treated with NSAID was 34 of $64(53 \%)$ compared with 43 of $60(72 \%)$ $(\mathrm{p}<0.05)$ in patients not taking NSAID, using the standard tests (see Table III). The differences did not reach statistical significance when the findings of the serological tests were compared in the presence or absence of NSAID.

$H$ pylori was identified in the gastric biopsy specimens of six of $17(35 \%)$ rheumatoid patients receiving long term gold injections plus NSAID, which is only two subjects less than the expected prevalence in such a subgroup had they taken 
TABLE III Detection of $\mathbf{H}$ pylori by serology compared with biopsy related tests (standard)

\begin{tabular}{llllll}
\hline & Standard & $\begin{array}{l}\text { Pyloriset } \\
\text { Latex }\end{array}$ & $\begin{array}{l}\text { Helico- } \\
G\end{array}$ & $\begin{array}{l}\text { Biolab } \\
\text { Malakit }\end{array}$ & $\begin{array}{l}\text { Bio-RadGAP } \\
\text { Test IgG }\end{array}$ \\
\hline On NSAID: & & & & & \\
True positives & 34 & 20 & 27 & 29 & 34 \\
True negatives & 30 & 15 & 14 & 15 & 9 \\
False positives & - & 15 & 16 & 15 & 21 \\
False negatives & - & 14 & 7 & 5 & - \\
Not on NSAID: & 43 & 26 & 32 & 35 & 41 \\
True positives & 17 & 12 & 10 & 11 & 5 \\
True negatives & - & 5 & 8 & 6 & 12 \\
False positives & - & 17 & 10 & 8 & 2 \\
False negatives & - & & & & \\
\hline
\end{tabular}

NSAID only; this did not change the overall statistical analyses of the study.

\section{Discussion}

This study shows that the sensitivity and specificity of three commercial serological tests (Pyloriset Latex, Helico-G, and Biolab Malakit) are lower than those of the standard biopsy related tests (culture, histology, and CLO test).

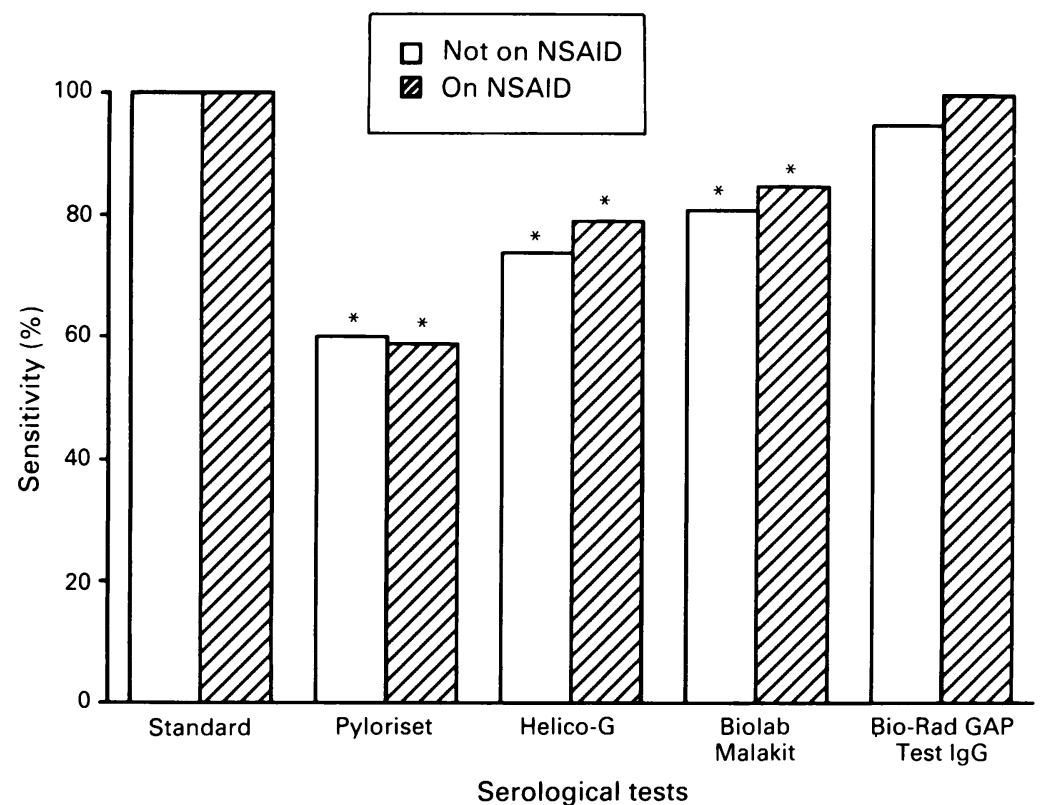

Figure 1: The sensitivity of the various serological tests in patients who were and were not taking NSAID. ${ }^{\star} p<0.05$ compared with standard biopsy related tests.

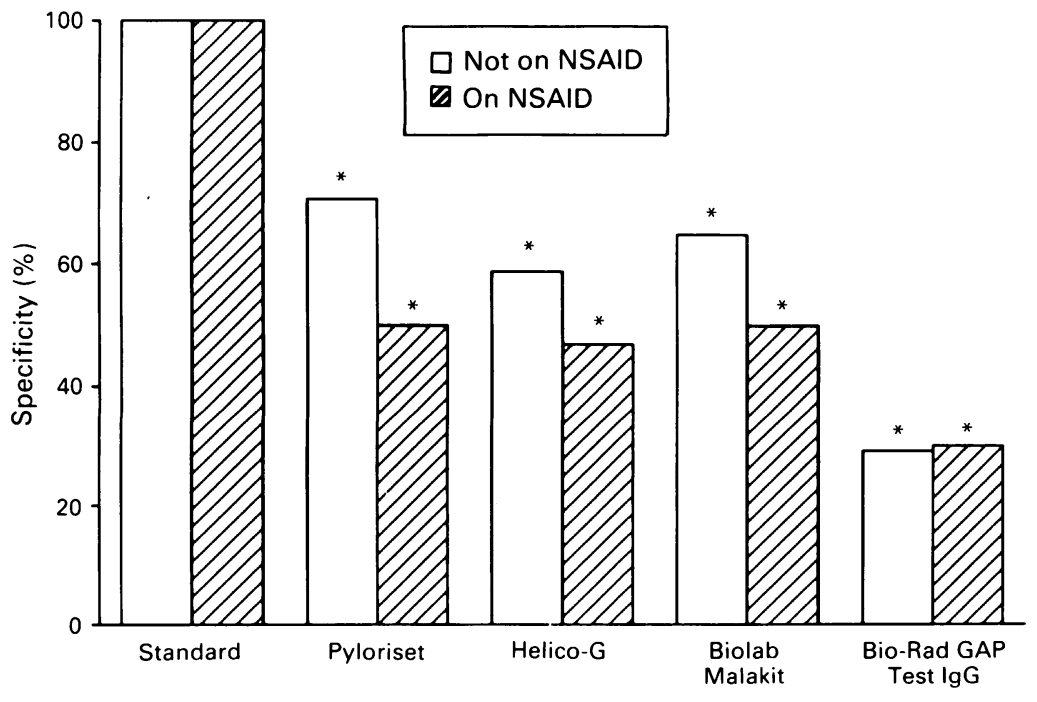

Serological tests

Figure 2: The specificity of the serological tests in patients who were and were not taking $N S A I D .{ }^{\star} p<0.05$ compared with standard biopsy related tests.
The specificity values of the above serological tests are also lower in patients receiving long term NSAID. The sensitivity of a fourth serological test, Bio-Rad GAP Test IgG, is identical to that of the standard tests but its specificity is significantly lower.

Several factors have recently been identified as being capable of influencing the performance of $H$ pylori serological tests: these include the patients' age, histological findings, $H$ pylori antigens, and, as suggested by this study, NSAID intake.

$H$ pylori infection and seropositivity have been shown to increase with age, ${ }^{19} 20$ although the immunological responses, in general, may be reduced in the elderly. ${ }^{21}$ Age is unlikely to have influenced the findings or the conclusions of our study, because all the tests and comparisons were carried out on the same group of patients.

Patients with certain histological abnormalities may be seropositive for $H$ pylori despite the failure to identify the organisms in their gastric biopsy specimens. This is particularly true for cases of chemical gastritis, as shown by this study and by others, ${ }^{8}$ and may explain, at least partly, the reduced specificity of serology in NSAID patients, who have a higher prevalence of chemical gastritis. ${ }^{1322}$ Similar findings have also been reported in patients with chronic atrophic gastritis ${ }^{2324}$ which suggests that they have been infected with $H$ pylori at some point in their lives. Atrophic gastritis was found in three of our patients and is therefore unlikely to have been an important factor in our study. However, it is worth noting that our findings refer to the presence of $H$ pylori in the antrum, the commonest site of such infection, and atrophy of the gastric body of our patients cannot, therefore, be excluded.

The development of serological assays for antibody responses to $H$ pylori antigens has been complicated by the fact that $H$ pylori organisms share antigens with other bacterial species, such as Campylobacter jejuni. ${ }^{25} 26$ A relatively high frequency of false positive and false negative results has been observed in studies using whole extracts of $H$ pylori as antigens. ${ }^{4025-27}$ More recently, higher sensitivity and specificity values have been reported when antibodies were raised against certain components of $H$ pylori organisms such as partially purified urease enzyme or high molecular weight cell associated proteins, ${ }^{7}$ and the $25 \mathrm{kDa}$ antigen of $H$ pylori. ${ }^{28}$ Another factor that needs to be considered is the fate of the antibody titres once their formation has been triggered by one or more of $H$ pylori antigens. It has been suggested that a considerable number of healthy people previously infected with $H$ pylori might remain seropositive despite the spontaneous elimination of the organisms..$^{29}$ This supports the hypothesis that $H$ pylori colonisation is a dynamic process with an active phase of infection and subsequent elimination of the bacteria in at least a proportion of infected people. ${ }^{29}$ Long term serological surveillance studies have also found that in most patients without $H$ pylori infection, 12 months after anti$H$ pylori therapy, both specific IgA and specific IgG antibody values were lower but had not yet returned to the normal range. ${ }^{30}$ These observa- 
tions, like chemical gastritis, might also help us understand the low specificity of our tests, especially in patients treated with NSAID, who have a low prevalence of $H$ pylori.

Very few studies have evaluated the serological tests described in our study. Despite being directed against relatively specific components of $H$ pylori, their sensitivity (excluding that of Bio-Rad GAP Test) and their specificity values are lower than some of the recently published data. Our findings with respect to Pyloriset Latex are similar to those of another report, ${ }^{31}$ but lower than the values described by another study, ${ }^{3}$ for unexplained reasons. The sensitivity and specficity of Helico-G in our study are also comparable with those of another, ${ }^{32}$ but it is worth noting that some workers ${ }^{9}$ had to modify the manufacturer's instructions in order to improve the performance of this test. Some authors ${ }^{7}$ have reported high sensitivity and specificity values for an ELISA test which, like Biolab Malakit, detects antibodies against partially purified urease antigen. However, the same test ${ }^{7}$ had been used by another group of workers $^{24}$ who found that 25 of $124(20 \%)$ patients studied were seropositive for $H$ pylori despite the absence of the organisms in their gastric biopsy specimens; 20 of the 25 false positive cases had atrophic gastritis. ${ }^{24}$

The sensitivity of Bio-Rad GAP Test IgG described in our study is almost identical to that found by another groups, ${ }^{8}$ but the lower specificity could be explained by one or more of the following: their reliance on histology as a standard, which might be difficult to interpret in the presence of very few organisms; the exclusion from their study of patients with chronic superficial or atrophic gastritis in whom $H$ pylor was not identified, thus reducing the number of true negatives; the relatively high number of cases of chemical gastritis in their $H$ pylori negative group without specifying whether these patients had been treated with NSAID; and the presence in their $H$ pylori positive group of chronic atrophic gastritis in 117 of $160(73 \%)$, which may have been paralleled by a rise in the number of false positive cases. ${ }^{2324}$

The lower specificity of Pyloriset Latex, Helico-G, and Biolab Malakit tests in NSAID patients could be explained by the presence of chemical gastritis ${ }^{8131622}$ and the low prevalence of $H$ pylori in these patients, as found by this study and by others. ${ }^{1334}$ The latter could be related to the impairment, by NSAID, of the gastric nucus layer, which is considered the natural habitat of $H$ pylori organisms. ${ }^{13}$ However, when these bacteria persist in the presence of NSAID, it has been suggested that the damaging effects of NSAID may become intensified. ${ }^{113}$ Threfore, accurate diagnosis of $H$ pylori in these patients is at least as important as it is in patients not taking NSAID.

In conclusion, this study has evaluated the efficacy of four commercial serological tests in comparison with standard biopsy related tests. Despite its high sensitivity, the Bio-Rad GAP Test IgG has been found to have low specificity. The Pyloriset Latex, Helico-G, and Biolab Malakit tests all had relatively low sensitivity and specificity, the latter being even lower in the presence of NSAID. These results could be related to the histological findings, the dynamic nature of $H$ pylori infection, the types of the antigens tested, NSAID intake, or some weaknesses in the manufacturers' instructions. These factors have to be considered in order to improve the reliability of serodiagnosis because of the potential advantages of these methods in identifying active $H$ pylori infection.

We thank Orion Diagnostica, Porton Cambridge, Biolab, and Bio$\mathrm{Rad}$ for donating some or all kits for the relevant serological tests. We also thank Miss Stephanie McLaughlin for performing the We also thank Miss Stephanie McLaughlin for performing the
statistical analyses, and Mrs Margaret Tosh for her secretarial assistance.

1 Das SS, Karim, QN, Easmon CSF. Opsonophagocytosis of Campylobacter pylori. $\mathcal{F}$ Med Microbiol 1988; 27: 125-30.

2 Jones DM, Lessels AM, Eldridge J. Campylobacter-like organisms in the gastric mucosa: culture, histological and serological studies. F Clin Pathol 1984; 37: 1002-6.

3 Westblom TU, Madan E, Czinn S, Gudipati S, Midkiff BR. Sensitivity and specificity of Pyloriset, a latex agglutination test for detection of Helicobacter pylori infection. Gastroenterology 1991; 100: A184.

4 Goodwin CS, Blincow E, Paterson C, et al. Enzyme-linked immunosorbent assay for Campylobacter pyloridis: correlation with presence of $\mathrm{C}$ pyloridis in the gastric musosa. F Infect Dis 1987; 155: 488-94.

5 Steer HW, Hawtin PR, Newell DG. An ELISA technique for the serodiagnosis of Campylobacter pyloridis infection in the serodiagnosis of Campylobacter pyloridis infection in
patients with gastritis and benign duodenal ulceration. patients with gastritis and benign
Serodiag Immunotherp 1987; 1: 253-9.

6 Perez-Perez GI, Dworkin BM, Chodos JE, Blaser MJ Campylobacter pylori antibodies in humans. Ann Int Med 1988; 109: 11-7.

7 Evans DJ, Evans DG, Graham DY, Klein PD. A sensitive and specific serologic test for detection of Campylobacter pylori infection. Gastroenterology 1989; 96: 1004-8.

8 Crabree JE, Shallcross TM, Heatley RV, Wyatt JI. Evaluation of a commercial ELISA for serodiagnosis of Helicobacter pylori infection. $\mathcal{F}$ Clin Pathol 1991; 44: 326-8.

9 Sobala GM, Crabtree JE, Pentith JA, Rathbone BJ, Shallcross MN, Wyatt JI, Dixon M, Heatley RV, Axon ATR. Screening dyspepsia by serology to Helicobacter pylori. Lancet 1991; ii: 94-6.

10 Graham DY. Helicobacter pylori and the endoscopist: whether to diagnose. Gastrointest Endosco 1991; 37: 577-9.

11 Jones STM, Clague RB, Eldridge J, Jones DM. Serological evidence of infection with Helicobacter pylori may predict gastrointestinal intolerance to non-steroidal antiinflammatory drug (NSAID) treatment in rheumatoid arthritis. Br F Rheumatol 1991; 30: 16-20.

12 Martin DF, Montgomery E, Dobek AS, Patrissi GA, Peura DA. Campylobacter pylori, NSAIDs, and smoking: risk factors for peptic ulcer disease. Am $\mathcal{F}$ Gastroenterol 1989; 84: 1268-72.

13 Taha AS, Nakshabendi I, Lee FD, Sturrock RD, Russell RI Chemical gastritis and Helicobacter pylori related gastritis in patients receiving non-steroidal anti-inflammatory drugs comparison and correlation with peptic ulceration. $\mathcal{f}$ Clin Pathol 1992; 45: 135-9.

14 Taha AS, Boothman P, Nakshabendi I, et al. Diagnostic tests for Helicobacter pylori - comparison and influence of nonfor Helicobacter pylori - comparison and influence of non708-12.

15 Taha AS, Boothman P, Holland P, et al. Gastric mucosal prostaglandin synthesis in the presence of Campylobacter pylori in patients with gastric ulcers and non-ulcer dyspepsia. Am $\mathcal{F}$ Gastroenterol 1990; 85: 47-50.

16 Dixon MF, O'Connor HJ, Axon ATR, King RFJG, Johnston D. Reflux gastritis: distinct histological entity. $\mathcal{F}$ Clin Pathol 1986; 39: 524-30.

17 Dixon MF, Wyatt J, Burk DA, Rathbone BJ. Lymphocytic gastritis - relationship to Campylobacter pylori infection. f Pathol 1988; 154: 125-32.

18 McNemar Q. Note on the sampling error of the difference between correlated proportions or percentages. Psycho-
metrica 1947; 12: 152-7.

19 Graham DY, Klein PD, Opekun AR, Boutton TW. Effect of age on the frequency of active Campylobacter pylori infection diagnosed by the $\left[\mathrm{C}^{13}\right]$ urea breath test in normal tion diagnosed by the $\left[\mathrm{C}^{13}\right]$ urea breath test in normal
subjects and patients with peptic ulcer disease. F Infect Dis subjects and patien

20 Jones DM, Eldrige JA, Fox AJ, Sethi P, Shorrell PJ. Antibody to the gastric Campylobacter-like organism 'Campylobacter pylorides' - clinical correlation and distribution in the normal population. $\mathcal{F}$ Med Microbiol 1986; 22: 57-62.

21 Horan MA, Fox RA. Ageing and the immune response - a unifying hypothesis? Mechanisms of Ageing and Development 1984; 26: 165-81.

22 Sobala GM, King RFG, Axon ATR, Dixon MF. Reflux 23 Fox JG, Correa P, Taylor NS, Zavala D, Fontham E, Janney $\mathrm{F}$, et al. Campylobacter pylori-associated gastritis and immune response in a population at increased risk of gastric immune response in a population at increased risk

24 Karnes WE, Samloff JM, Sisurala M, Kekki M, Sipponen P, Kim SWR, et alPositive serum antibody and negative tissue staining for Helicobacter pylori in subjects with
body gastritis. Gastroenterology 1991; 101: 167-74. 
25 Perez-Perez GI, Blaser MJ. Conservation and diversity of Campylobacter pyloridis major atigens. Infect Immun 1987; 55: 1256-63.

26 Rathbone BJ, Wyatt JI, Worsley BW, Shires SE, Trejdosiewicz LK, Heatley RV, et al Systemic and local antibody responses to gastric Campylobacter pyloridis in non-ulcer dyspepsia. Gul $1986,27.642-7$.

27 Newell DG. Identification of the outer membrane proteins of Campylobacter pyloridis and antigen cross-reactivity between C. pyloridis and $C$ jejuni. $\mathcal{F}$ Gen Microbiol 1987 133: 163-70.

28 Sugiyama T, Imai K, Yoshida H, Takayama Y, Yabana T, Yokota $\mathrm{K}$, et al. A novel enzyme immunoassay for serodiagnosis of Helicobacter pylori infection. Gastroenterology 1991; 101: 77-83.

29 Meyer B, Werth B, Beglinger C, Dill S, Drewe J, Vischer WA, et al. Helicobacter pylori infection in healthy people: a dynamic process? Gut 1991; 32: 347-50.
30 Veenedaal RA, Pena AS, Meijer JL, Endtz HPN, van der Est MMC, van Duijn W, et al. Longterm surveillance after MMC, van Duijn W, et al. Longterm surveillance after 1291-4.

31 Megraud F, Azelsson C, Bouchard S, Camon C. Comparison of kits to detect circulating Helicobacter pylori IgG antibodies. Gastroenterology 1991; 100: A123.

32 Ching CK. Screening for Helicobacter pylori in dyspepsia. Lancet 1991; ii: 394.

33 Marshall BJ, McGechie DB, Rogers PA, Glancy RJ. Pyloric Campylobacter infections and gastroduodenal disease. Campylobacter infections and
Med $\mathcal{F}$ Aust $1985 ; 142: 439-44$.

34 Caselli M, Pazzi P, Laconte R, Aleotti A, Trevisani L, Stabellini G. Campylobacter-like organisms, non-steroidal anti-inflammatory drugs and gastric lesions in patients with anti-inflammatory drugs and gastric lesions in
rheumatoid arthritis. Digestion 1989; 44: 101-4. 